OPEN ACCESS

Edited by:

Abd El-Latif Hesham,

Assiut University, Egypt

Reviewed by:

Birgit Mitter,

Austrian Institute of Technology,

Austria

Andrea Campisano,

Fondazione Edmund Mach, Italy

*Correspondence:

Changlong Shu

clshu@ippcaas.cn

Jiangyan Duan

duanjiangyan123@163.com

tThese authors have contributed equally to this work.

Specialty section:

This article was submitted to Technical Advances in Plant Science,

a section of the journal

Frontiers in Plant Science

Received: 06 April 2017 Accepted: 05 September 2017 Published: 26 September 2017

Citation:

Tian X, Shi Y, Geng L, Chu H, Zhang J, Song F, Duan J and Shu C (2017) Template Preparation Affects

$16 S$ rRNA High-Throughput Sequencing Analysis of Phyllosphere

Microbial Communities.

Front. Plant Sci. 8:1623.

doi: 10.3389/fpls.2017.01623

\section{Template Preparation Affects 16S rRNA High-Throughput Sequencing Analysis of Phyllosphere Microbial Communities}

\author{
Xiaoyan Tian',2t, Yu Shist, Lili Geng ${ }^{1}$, Haiyan $\mathrm{Chu}^{3}$, Jie Zhang ${ }^{1}$, Fuping Song ${ }^{1}$, \\ Jiangyan Duan ${ }^{2 *}$ and Changlong Shu ${ }^{1 *}$
}

${ }^{1}$ State Key Laboratory for Biology of Plant Diseases and Insect Pests, Institute of Plant Protection, Chinese Academy of Agricultural Sciences, Beijing, China, ${ }^{2}$ School of Life Sciences, Shaanxi Normal University, Linfen, China, ${ }^{3}$ State Key Laboratory of Soil and Sustainable Agriculture, Institute of Soil Science, Chinese Academy of Sciences, Nanjing, China

Phyllosphere microbial communities are highly diverse and have important ecological implications; in that context, bacterial identification based on 16S rRNA genes is an important research issue. In studies of phyllosphere microbial communities, microporous filtration and centrifugation are used to collect microorganism samples, but it is unclear which one has a better collection efficiency. In this study, we compared these two microorganism collection methods and investigated the effects of the DNA extraction process on the estimation of microbial community composition and organization. The following four treatments were examined: (A) filtration, resuspension, and direct PCR; (B) filtration, DNA isolation, and PCR; (C) centrifugation, resuspension, and direct PCR; (D) centrifugation, DNA isolation, and PCR. Our results showed that the percentage of chloroplast sequence contaminants was affected by the DNA extraction process. The bacterial compositions clearly differed between treatments $A$ and $C$, suggesting that the collection method has an influence on the determination of community structure. Compared with treatments $B$ and $D$, treatments $A$ and $C$ resulted in higher Shannon index values, indicating that the DNA extraction process might reduce the observed phyllosphere microbial alpha diversity. However, with respect to community structure, treatments B and D yielded very similar results, suggesting that the DNA extraction process erases the effect of the collection method. Our findings provide key information to ensure accurate estimates of diversity and community composition in studies of phyllosphere microorganisms.

\section{Keywords: phyllosphere, template, method, 16S rRNA gene, amplicon sequencing}

\section{INTRODUCTION}

The phyllosphere is an important habitat for microbes and is colonized by a large number of microbial taxa. The global population of phyllosphere microbes is estimated to be $\sim 10^{26}$ cells (Lindow and Brandl, 2003). Culture-based isolation studies have shown that phyllosphere microbial communities include many important taxa, including plant pathogens, ice nucleationactive bacteria (Hirano and Upper, 2000), decomposers (Hicks and Silvester, 1985), phytohormone 
producers (Fett et al., 1987), nitrogen fixers (Furnkranz et al., 2008), and antagonists of plant pathogens (WeymanKaczmarkowa and Pedziwilk, 2001). Phototrophic microbes also colonize some plant leaves, including rhodopsin-based ones, absorbing different fractions of the light spectrum (Atamna-Ismaeel et al., 2012b). These findings indicate that the phyllosphere microbial community is closely related to phyllosphere functions and further studies are likely to discover new ecological interactions. Currently, both culturedependent and culture-independent methods are used to analyze phyllosphere microorganisms. The culture-independent methods can detect a broader microbial diversity and are widely used for microbial community analyses, primarily using 16S rRNA gene amplicon sequencing to determine the composition, organization, and spatiotemporal patterns of microbial communities.

Current data indicate that bacteria occupy the majority of the plant leaf surface, ranging from $10^{6}$ to $10^{7}$ bacteria $/ \mathrm{cm}^{2}$ (Lindow and Leveau, 2002). This concentration is lower than in other environmental samples, e.g., soil, and so a reliable and efficient bacterial collection and PCR template preparation process is needed. This process includes three main steps. First, microorganisms need to be dislodged from leaves; a sonication separation method is typically used in this step. Second, microorganisms have to be collected; two methods are used for this purpose: the microporous filtration method (Atamna-Ismaeel et al., 2012b) and the centrifugation method (Yang et al., 2001). Third, microorganism DNA is extracted using an appropriate kit (Yang et al., 2001; Atamna-Ismaeel et al., 2012b); this DNA is then used as a template for $16 \mathrm{~S}$ rRNA gene amplicon sequencing. However, there is no consensus on the best collection method, therefore, in this study, we compared the effectiveness of different methods. Furthermore, we also investigated the effect of the DNA extraction process on estimates of microbial community composition and diversity.

The Brassicaceae are a large eudicot family and include the model plant Arabidopsis thaliana. Brassica napus L. was formed by recent allopolyploidy and diversifying selection gave rise to oilseed rape (canola), rutabaga, fodder rape, and kale morphotypes grown for oil, fodder, and food (Chalhoub et al., 2014). Analysis of the phyllosphere microbes of B. napus L. can not only help us understand the plant-microbe ecological interactions, but also provide ideas for B. napus L. insect and disease control in agriculture. In the current study, our results provide a guideline for facilitating future studies on. phyllosphere microbial communities.

\section{MATERIALS AND METHODS}

\section{Culture and Sample Collection}

Brassica napus L. was selected for the analysis and the soil used to grow $B$. napus L. was collected at the Institute of Plant Protection, Chinese Academy of Agricultural Sciences. B. napus L. was cultured in a phytotron under the following cultivation conditions: $14 \mathrm{~h}$ (7000 Lux) illumination and $10 \mathrm{~h}$ dark, average relative humidity of $64 \%$, temperature of $18^{\circ} \mathrm{C}$ to $23^{\circ} \mathrm{C}$. Samples were collected in 2016 and leaves of similar sizes from three individual plants were cut from the stem and washed with phosphate-buffered saline (PBS) solution.

\section{Bacterial Community Collection and PCR Template Preparation}

The method was modified from the protocols described by Yang et al. (2001) and Atamna-Ismaeel et al. (2012b). The dust on the leaves was washed off with PBS. The leaves were then placed in $50-\mathrm{mL}$ tubes, submerged in $40 \mathrm{~mL}$ of wash buffer (0.1 M potassium phosphate buffer saline, $\mathrm{pH} 7.0$ ), and sonicated for $10 \mathrm{~min}$ in an ultrasonic cleaning bath (Bransonic 32) for 10 min to dislodge bacteria (Figure 1, Step 1). Then, the wash buffer with dislodged microorganisms was divided into four marked A, B, C, and D. The microorganisms in A and $B$ were collected using Millipore $(0.2 \mu \mathrm{m})$ filtration (Billerica, MA, United States) (Figure 1, Step 2a), while C and D were collected by centrifugation $(10,000 \times g$ for $15 \mathrm{~min})$ (Figure $\mathbf{1}$, Step 2b). For treatments A and B, the filters were dismantled, the microorganisms in the filter membrane were resuspended in $100 \mu \mathrm{L}$ of sterilized PBS by vortexing the minced filter membrane for $2 \mathrm{~min}$, and the total microorganismal DNA in $\mathrm{B}$ was extracted using the Fast-DNA Kit (Axygen ${ }^{\circledR}$ Corning Life Sciences, Wujiang, China) according to the manufacturer's instructions (Figure 1, Step 3a, 3b). For treatments C and D, the microorganisms were resuspended in $100 \mu \mathrm{L}$ of sterilized PBS. The microorganismal DNA in D was extracted using the FastDNA Kit (Figure 1, Step 3c, 3d). Then, $1 \mu \mathrm{L}$ (about $3 \mathrm{ng}$ ) of DNA from treatment B or D was used as a template for PCR amplification, for samples A and C $1 \mu \mathrm{L}$ of the microorganism suspension was used as a template for direct PCR. Three replicates were performed for each treatment.

\section{S rRNA Amplification and Amplicon Sequencing}

The V4 hypervariable region of the 16S rRNA gene was selected for amplicon sequencing of the phyllosphere microbial community using the universal forward primer 515F (5'-GTGCCAGCMGCCGCGGTAA- $\left.3^{\prime}\right)$ and the 6-bp uniquely barcoded reverse sequencing primer $806 \mathrm{R}\left(5^{\prime}-\mathrm{NN}\right.$ NNNNGGACTACVSGGGTATCTAAT-3') (Bokulich et al., 2012) (Table 1). PCR was performed as follows: $10 \mathrm{~min}$ of initial denaturation at $95^{\circ} \mathrm{C}, 30$ cycles at $94^{\circ} \mathrm{C}$ for $1 \mathrm{~min}, 55^{\circ} \mathrm{C}$ for $1 \mathrm{~min}$, and $72^{\circ} \mathrm{C}$ for $1 \mathrm{~min}$, and a final extension at $72^{\circ} \mathrm{C}$ for $10 \mathrm{~min}$. PCR amplicons were analyzed by $2 \%$ agarose gel electrophoresis and purified using the AxyPrep DNA Gel Extraction Kit (Axygen AP-GX-250). The purified DNA was quantified by Qubit (Thermo Fisher Scientific, United States) according to the manufacturer's instructions. Equal amounts of PCR amplicons were mixed in a single sample. The amplicons were extended with Illumina-specific adaptors (San Diego, CA, United States) using the TruSeq ${ }^{\circledR}$ DNA PCR-Free Sample Preparation Kit, and the resulting libraries were sequenced using Illumina HiSeq 2500 technology $(2 \times 250 \mathrm{bp})$. During this process, DNA was quantified by Qubit or quantitative PCR, as appropriate. 


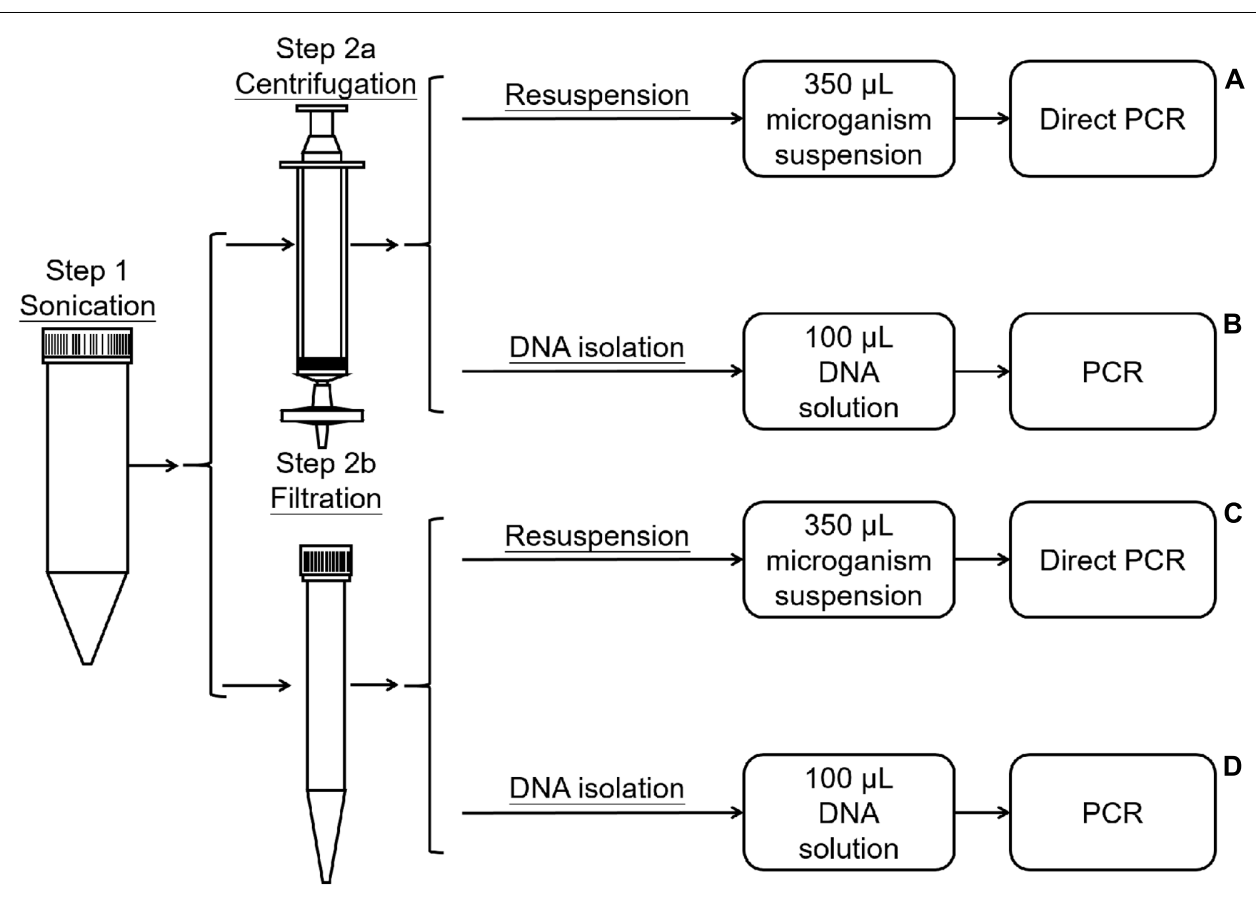

FIGURE 1 | Process of bacterial collection and DNA extraction.

\section{Sequence Read Processing and Construction of Operational Taxonomic Unit (OTU) Tables}

Before assembly, low-quality reads from the raw sequences were filtered according to the following rules: (1) reads containing only the adaptor sequence; (2) reads containing unknown nucleotides " $N$ " in over $5 \%$ of positions; and (3) low-quality reads (defined as reads containing bases with a quality value of less than 15

TABLE 1 | Analysis of chloroplast contamination and OTUs based on different read counts.

\begin{tabular}{lccccc}
\hline Sample & Barcode & HQS & CCP $\%$ & OTUs & SRA \\
\hline A1 & GTTCG & 202797 & 90.25 & 284 & SRR5852956 \\
A2 & CGTACG & 152325 & 80.18 & 266 & SRR5852952 \\
A3 & GAGTGG & 167059 & 86.14 & 271 & SRR5852938 \\
B1 & GGTAGC & 39184 & 61.29 & 172 & SRR5852944 \\
B2 & ACTGAT & 161846 & 18.72 & 160 & SRR5852947 \\
B3 & ATGAGC & 137316 & 6.99 & 156 & SRR5852933 \\
C1 & ATTCGG & 75253 & 25.12 & 151 & SRR5852931 \\
C2 & CAAAAG & 119526 & 16.10 & 162 & SRR5858743 \\
C3 & CAACTA & 119719 & 9.74 & 150 & SRR5858747 \\
D1 & CACCGG & 151349 & 31.96 & 169 & SRR5858744 \\
D2 & CACGAT & 137164 & 5.90 & 154 & SRR5858746 \\
D3 & CACTCA & 149852 & 6.38 & 198 & SRR5858745 \\
\hline
\end{tabular}

HQS, High-quality sequences produced from each sample. CCP, chloroplast contaminant percentage from 35000 High-quality sequences from each sample. OTUs, the operational taxonomic units produced from 7000 High-quality bacterial sequences. SRA, the accession numbers of sequence read archives deposited in NCBI. occupying more than $20 \%$ of the entire read). PANDAseq was employed to correct sequence errors and merge Illumina pairedend reads to produce high-quality $16 \mathrm{~S}$ rRNA V4 hypervariable region sequences. All processes were performed using default parameters. The UCHIME "Gold" database was used to eliminate chimeric sequences, and characteristic sequences of OTUs were selected (Edgar et al., 2011). Uparse (Usearch version 8.0.1517) (Edgar, 2013) was used to generate the 16S rRNA OTU table and determine OTU abundance. The threshold value for V4 hypervariable region identity was set to $97 \%$. The highest frequency OTUs were determined as representative OTU sequences. The representative OTU sequences were annotated using the Ribosomal Database Project (RDP version 2.2) classifier Greengenes (version 13.8) (Wang et al., 2007).

\section{Downstream Data Analysis and Statistics}

To assess chloroplast sequence contamination in the data sets, 35000 sequences were randomly selected for each treatment, OTU tables were constructed, and representative OTU sequences were annotated. The abundance of representative chloroplast OTUs was determined. To analyze the bacterial community composition and structure for each treatment (A, B, C, and D), data sets were normalized by randomly selecting 7000 sequences (excluding chloroplast sequences) for further analysis. The OTU table construction, OTU abundance estimation, and representative OTU sequence annotation for the 7000 bacterial sequences were performed as described before.

Alpha-diversity (i.e., within sample diversity) metrics were calculated to estimate sample community diversity using mothur (version 1.36.1) (Schloss et al., 2009). Variation between samples 
was calculated based on UniFrac distances, and a distance matrix was built. Weighted UniFrac distances were obtained using species abundance information and weighted branch lengths were obtained using abundance information (Lozupone and Knight, 2005). A principal coordinate analysis plot based on weighted UniFrac distances was obtained using $\mathrm{R}$ software (version 2.15.3) to visualize complex relationships between samples (Park et al., 2014).

\section{RESULTS}

\section{Chloroplast Sequence Contamination}

After quality control and assembly, the number of high-quality sequences for each sample ranged from 39184 to 202797 (Table 1). To assess chloroplast sequence contamination, 35000 high-quality sequences from each treatment were randomly selected for analysis. After OTU table construction and representative OTU sequence annotation, sequence abundance data showed that treatment A resulted in an extremely high percentage $(>80 \%)$ of chloroplast sequences (Table 1) The other samples gave a lower percentage although there was a large variation between different replicates.

\section{Diversity Analysis}

The top 10 phyla and genera based on relative abundances were compared among the four treatments (Figure 2). The microbial community from $B$. napus L. leaves obtained using the four treatment methods were dominated by Proteobacteria. The percentages of Proteobacteria in treatment A, B, C, and D were 78.43\% (standard deviation, 2.95\%), 90.23\% (standard deviation, 0.97\%), 92.80\% (standard deviation, 0.49\%) and $89.99 \%$ (standard deviation, 1.81\%) respectively. At the genus level, the microbiota was dominated by Serratia, which was present at $25.88 \%$ for treatment A, $55.66 \%$ for treatment B, $28.22 \%$ for treatment C, and $55.10 \%$ for treatment D. Stenotrophomonas, Acinetobacter, Delftia, Pandoraea, Citrobacter, Pseudomonas, Bacillus, Rhodococcus, and Staphylococcus were also identified and their relative abundance was affected by template preparation method (Figure 2).

We compared the Shannon index values obtained for samples prepared using treatments $\mathrm{A}$ and $\mathrm{C}$, both of which used direct PCR, to determine the effect of collection method. The leaf microbiota collected by Millipore filtration (treatment A) was more diverse than that collected by centrifugation (treatment C) $(P<0.01)$ (Figure 3). When comparing the effect of the DNA extraction process on microbiota diversity, the Shannon index values were significantly lower for samples subjected to DNA extraction (treatments B and D) than for those subjected to direct PCR (A and C). In addition, there was no significant difference in Shannon index values between samples subjected to DNA extraction in treatments B and D. The lower Shannon index values obtained for treatments $\mathrm{B}$ and $\mathrm{D}$ compared to treatments $\mathrm{A}$ and $\mathrm{C}$ suggested that the DNA extraction process results in lower estimates of community diversity.

A principal coordinate analysis revealed distinct bacterial communities among the four treatments (Figure 4). Principal

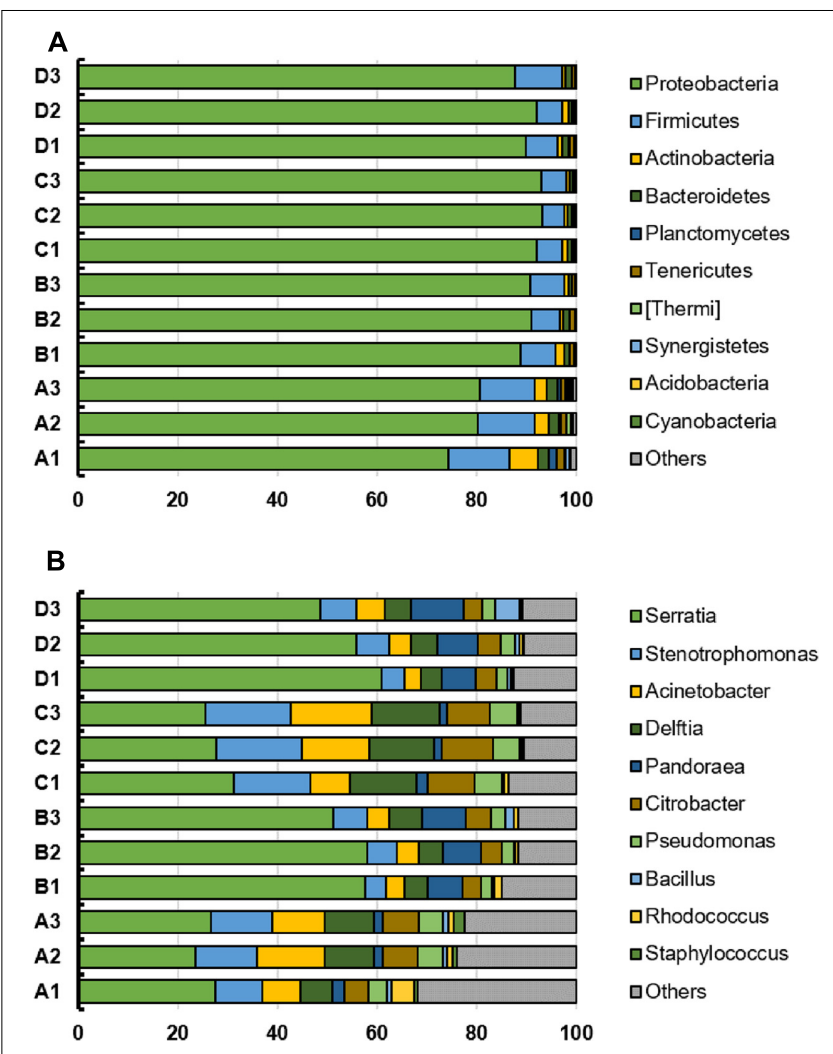

FIGURE 2 | (A,B) Top 10 phyla and genera in individual bacterial communities from the $B$. napus $L$. phyllosphere for the four treatments $(A, B, C, D)$. The $x$-axis indicates the relative abundance.

component 1 (PC1) and PC2 accounted for 60.15 and $29.37 \%$ of the community variation, respectively. Samples in the same treatment group clustered together. In particular, the bacterial communities obtained for treatments $\mathrm{A}$ and $\mathrm{C}$ were differentiated, suggesting that the community collection method affects the community structure. Additionally, bacterial community data obtained for treatments $\mathrm{B}$ and $\mathrm{D}$ were different from those for treatments $\mathrm{A}$ and $\mathrm{C}$, indicating that the DNA extraction process could affect community structure as well. However, the bacterial community data obtained for treatments $\mathrm{B}$ and $\mathrm{D}$ could not be distinguished, and the ellipse areas, which represent the $95 \%$ confidence intervals, overlapped. These results suggest that the DNA extraction process could eliminate the differences generated by the sample collection method.

\section{DISCUSSION}

Green plants are primary producers that can manufacture inorganic nutrients via photosynthesis, with the leaves being the main site of photosynthesis. Previous work has demonstrated the importance of characterizing the phyllosphere microbial community, which contains many functionally important microbes. The 16S rRNA gene amplicon sequencing 


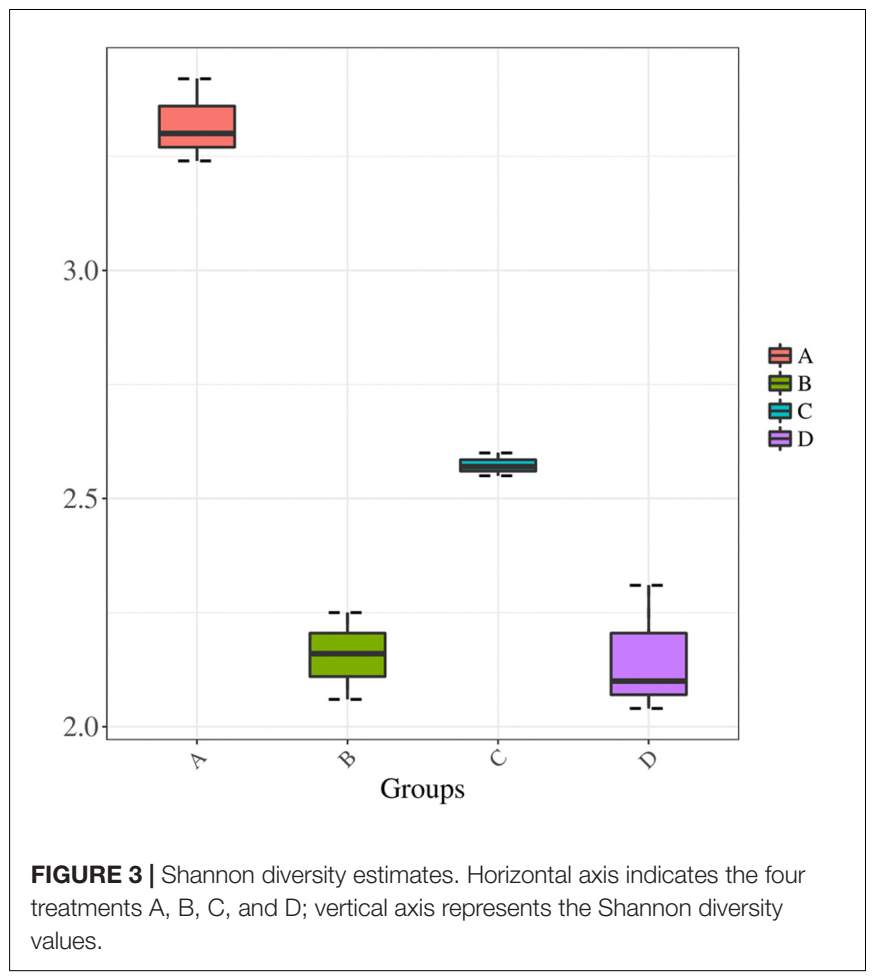

strategy has been successfully applied in studies of the composition, organization, and spatiotemporal patterns of microbial communities and is important to improve our understanding of phyllosphere microbial communities (Yang et al., 2001; Atamna-Ismaeel et al., 2012a). Several methods have been used for template preparation for $16 \mathrm{~S}$ rRNA gene amplicon sequencing. In this study, we evaluated the effectiveness of the template preparation methods in $16 \mathrm{~S}$ rRNA gene amplicon sequencing and microbial community analyses.

Normally, the first step in template preparation is to dislodge microorganisms from leaves. Separation by sonication and brush rubbing has been used for this purpose. In addition, Suda et al. (2008) attempted the direct extraction of phyllosphere microbial DNA using chemical reagents, without the dislodging step. In this study, we used sonication separation to dislodge microorganisms from leaves because the brush rubbing method is complex and not highly reproducible; furthermore, another study (Ali et al., 2015) indicated that the DNA produced using the latter method contains substantial chloroplast contamination.

We then evaluated the two main microorganism cell collection methods, i.e., microporous filtration (Atamna-Ismaeel et al., 2012b) and centrifugation (Yang et al., 2001). The microporous filtration method filters out microorganism cells that exceed the size of the pores $(0.2 \mu \mathrm{m})$ in the filter membrane, while the centrifugation method collects microorganism cells with greater densities than that of the solution. In this study, we compared the effectiveness of the two collection methods using direct PCR (treatments $\mathrm{A}$ and $\mathrm{C}$ ). The microporous filtration method resulted in

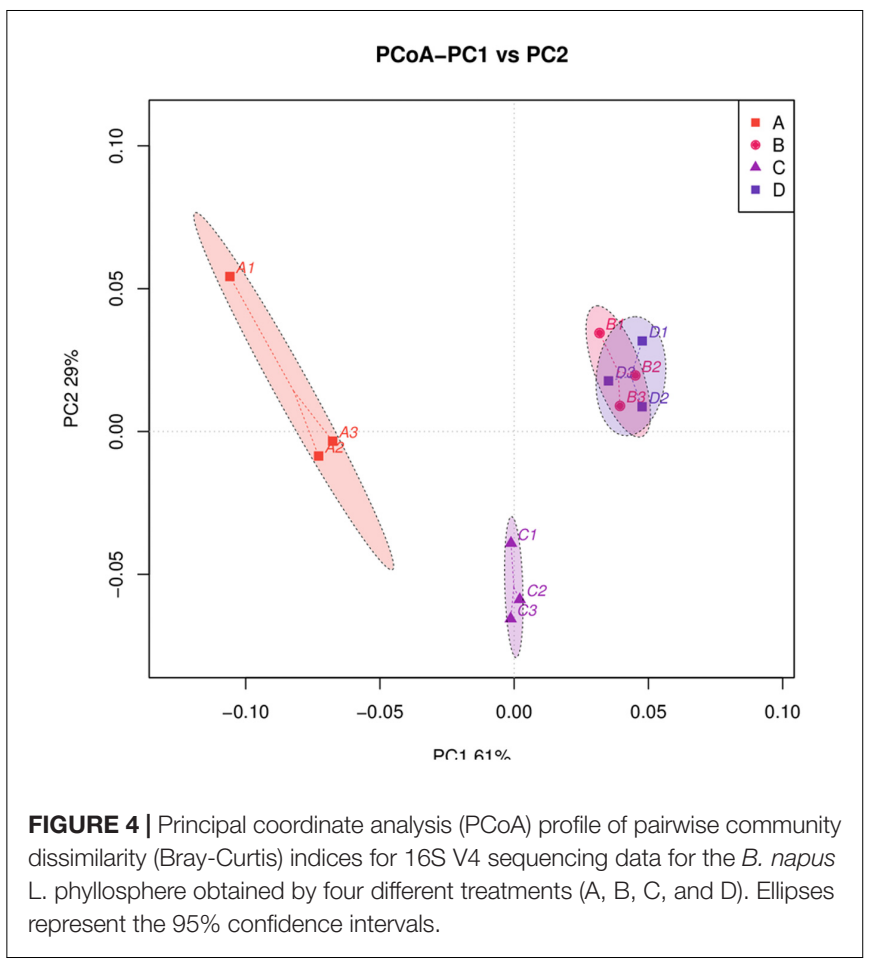

a higher Shannon index value and also produced more OTUs (Table 1). These data suggest that the microporous filtration method is more effective for the collection of microorganisms, it did not miss microorganism cells that are not easy collected by centrifugation, e.g., microorganisms with cell densities that are not significantly greater than that of the solution.

In addition, we evaluated the effects of the DNA extraction process on microbial community analyses. DNA extraction is often necessary, e.g., in analyses of rhizosphere and intestinal microbial communities. However, the precise DNA extraction method may affect the results of these analyses. This issue has two main explanations. First, different bacterial groups (gramnegative, gram-positive, etc.) demonstrate different degrees of resistance to chemical agents or cell disruption treatments in protocols for DNA extraction (Wintzingerode et al., 1997; Nelson et al., 2010). Therefore, in some cases, bacterial cell walls cannot be broken sufficiently (depending on the composition and structure of the wall) and DNA is not released into the solution. Second, the chemical agents might lyse cells effectively, but damage DNA in the process. This leads to the underestimation and/or overestimation of some bacterial groups in the microbial community. In this study, we evaluated the effects of the PCR template preparation process on microbial community analyses (treatments B and D) by comparison with data obtained by direct PCR (treatments A and C). The DNA extraction process was associated with a lower Shannon index value. The sequence number in the OTUs table (Supplementary Table 1) also suggested that some bacterial groups as well as chloroplast DNA (Table 1) were not released or degraded during the extraction process while other bacterial groups were released 
more efficiently. With respect to the DNA extraction process, the microbial community samples obtained using different collection methods (treatment A and C) differed. When we compared the microbial community data obtained for treatments B and D, with an added DNA extraction step, with those for treatments $A$ and $\mathrm{C}$, there was no significant difference. These results suggested that the current DNA extraction method did bias the community analysis. Therefore, the DNA extraction method still needs to be improved.

\section{CONCLUSION}

Based on the data obtained in this study, we suggest that microporous filtration is the preferred method for microbial cell collection to obtain a comprehensive summary of the microbial community when chloroplast contamination is acceptable. However, if it is critical to minimize chloroplast contamination, the centrifugation method is also acceptable. But, extracted DNA method is less efficient for the analysis of microbial diversity.

\section{REFERENCES}

Ali, N., Al-Awadhi, H., Dashti, N., Khanafer, M., El-Nemr, I., Sorkhoh, N., et al. (2015). Bioremediation of atmospheric hydrocarbons via bacteria naturally associated with leaves of higher plants. Int. J. Phytoremediation 17, 1160-1170. doi: 10.1080/15226514.2015.1045125

Atamna-Ismaeel, N., Finkel, O., Glaser, F., von Mering, C., Vorholt, J. A., Koblizek, M., et al. (2012a). Bacterial anoxygenic photosynthesis on plant leaf surfaces. Environ. Microbiol. Rep. 4, 209-216. doi: 10.1111/j.1758-2229.2011. 00323.x

Atamna-Ismaeel, N., Finkel, O. M., Glaser, F., Sharon, I., Shneider, R., Post, A. F., et al. (2012b). Microbial rhodopsins on leaf surfaces of terrestrial plants. Environ. Microbiol. 14, 140-146. doi: 10.1111/j.1462-2920.2011. 02554.x

Bokulich, N. A., Joseph, C. M., Allen, G., Benson, A. K., and Mills, D. A. (2012). Next-generation sequencing reveals significant bacterial diversity of botrytized wine. PLOS ONE 7:e36357. doi: 10.1371/journal.pone.003 6357

Chalhoub, B., Denoeud, F., Liu, S., Parkin, I. A., Tang, H., Wang, X., et al. (2014). Plant genetics. Early allopolyploid evolution in the post-Neolithic Brassica napus oilseed genome. Science 345, 950-953. doi: 10.1126/science.125 3435

Edgar, R. C. (2013). UPARSE: highly accurate OTU sequences from microbial amplicon reads. Nat. Methods 10, 996-998. doi: 10.1038/nmeth. 2604

Edgar, R. C., Haas, B. J., Clemente, J. C., Quince, C., and Knight, R. (2011). UCHIME improves sensitivity and speed of chimera detection. Bioinformatics 27, 2194-2200. doi: 10.1093/bioinformatics/btr381

Fett, W. F., Ossman, S. F., and Dunn, M. F. (1987). Auxin production by plantpathogenic pseudomonads and xanthomonads. Appl. Environ. Microbiol. 53, 1839-1845.

Furnkranz, M., Wanek, W., Richter, A., Abell, G., Rasche, F., and Sessitch, A. (2008). Nitrogen fixation by phyllosphere bacteria associated with higher plants and their colonizing epiphytes of a tropical lowland rainforest of Costa Rica. ISME J. 2, 561-570. doi: 10.1038/ismej.2008.14

Hicks, B. J., and Silvester, W. B. (1985). Nitrogen fixation associated with the New Zealand mangrove (Avicennia marina (Forsk.) Vierh. var. resinifera (Forst. f.) Bakh.). Appl. Environ. Microbiol. 49, 955-959.

Hirano, S. S., and Upper, C. D. (2000). Bacteria in the leaf ecosystem with emphasis on Pseudomonas syringae-a pathogen, ice nucleus, and epiphyte.

\section{AUTHOR CONTRIBUTIONS}

Design of experiment by CS, JD, YS, LG, HC, FS, JZ, and XT. Experiments performed by XT, CS, YS, and LG. First draft done of the paper by XT, and CS. Suggestions of this paper made by YS, FS, and HC.

\section{ACKNOWLEDGMENTS}

This study was supported by the National Key Research and Development Program of China (2017YFD0201204 and 2017YFD0200604) and National Natural Science Foundation of China (Nos. 31530095 and 41701298).

\section{SUPPLEMENTARY MATERIAL}

The Supplementary Material for this article can be found online at: http://journal.frontiersin.org/article/10.3389/fpls.2017.01623/ full\#supplementary-material

Microbiol. Mol. Biol. Rev. 64, 624-653. doi: 10.1128/MMBR.64.3.624-653. 2000

Lindow, S. E., and Brandl, M. T. (2003). Microbiology of the phyllosphere. Appl. Environ. Microbiol. 69, 1875-1883. doi: 10.1128/AEM.69.4.1875-1883. 2003

Lindow, S. E., and Leveau, J. H. J. (2002). Phyllosphere microbiology. Curr. Opin. Biotechnol. 13, 238-243. doi: 10.1016/S0958-1669(02) 00313-0

Lozupone, C., and Knight, R. (2005). UniFrac: a new phylogenetic method for comparing microbial communities. Appl. Environ. Microbiol. 71, 8228-8235. doi: 10.1128/AEM.71.12.8228-8235.2005

Nelson, E. A., Palombo, E., and Knowles, S. R. (2010). Comparison of methods for the extraction of bacterial DNA from human faecal samples for analysis by realtime PCR. Curr. Res. Technol. Educ. Topics Appl. Microbiol. Microb. Biotechnol. 2, 1479-1485.

Park, H., Shin, J. W., Park, S. G., and Kim, W. (2014). Microbial communities in the upper respiratory tract of patients with asthma and chronic obstructive pulmonary sisease. PLOS ONE 9:e109710. doi: 10.1371/journal.pone. 0109710

Schloss, P. D., Westcott, S. L., Ryabin, T., Hall, J. R., Hartmann, M., Hollister, E. B., et al. (2009). Introducing mothur: open-source, platform-independent, community-supported software for describing and comparing microbial communities. Appl. Environ. Microbiol. 75, 7537-7541. doi: 10.1128/AEM. 01541-09

Suda, W., Oto, M., Amachi, S., Shinoyama, H., and Shishido, M. (2008). A direct method to isolate DNA from phyllosphere microbial communities without disrupting leaf tissues. Microbes Environ. 23, 248-252. doi: 10.1264/jsme2. 23.248

Wang, Q., Garrity, G. M., Tiedje, J. M., and Cole, J. R. (2007). Naive Bayesian classifier for rapid assignment of rRNA sequences into the new bacterial taxonomy. Appl. Environ. Microbiol. 73, 5261-5267. doi: 10.1128/AEM. 00062-07

Weyman-Kaczmarkowa, W., and Pedziwilk, Z. (2001). Epiphytic microflora of poplar clones susceptible and resistant to infection by Dothichiza populea. Microbiol. Res. 156, 83-86. doi: 10.1078/0944-501300074

Wintzingerode, F., Gobel, U. B., and Stackebrandt, E. (1997). Determination of microbial diversity in environmental samples: pitfalls of PCR-based rRNA analysis. FEMS Microbiol. Rev. 21, 213-229. doi: 10.1111/j.1574-6976.1997. tb00351.x 
Yang, C. H., Crowley, D. E., Borneman, J., and Keen, N. T. (2001). Microbial phyllosphere populations are more complex than previously realized. Proc. Natl. Acad. Sci. U.S.A. 98, 3889-3894. doi: 10.1073/pnas.051633898

Conflict of Interest Statement: The authors declare that the research was conducted in the absence of any commercial or financial relationships that could be construed as a potential conflict of interest.
Copyright (C) 2017 Tian, Shi, Geng, Chu, Zhang, Song, Duan and Shu. This is an open-access article distributed under the terms of the Creative Commons Attribution License (CC BY). The use, distribution or reproduction in other forums is permitted, provided the original author(s) or licensor are credited and that the original publication in this journal is cited, in accordance with accepted academic practice. No use, distribution or reproduction is permitted which does not comply with these terms. 